\title{
Highlights from RöKo International
}

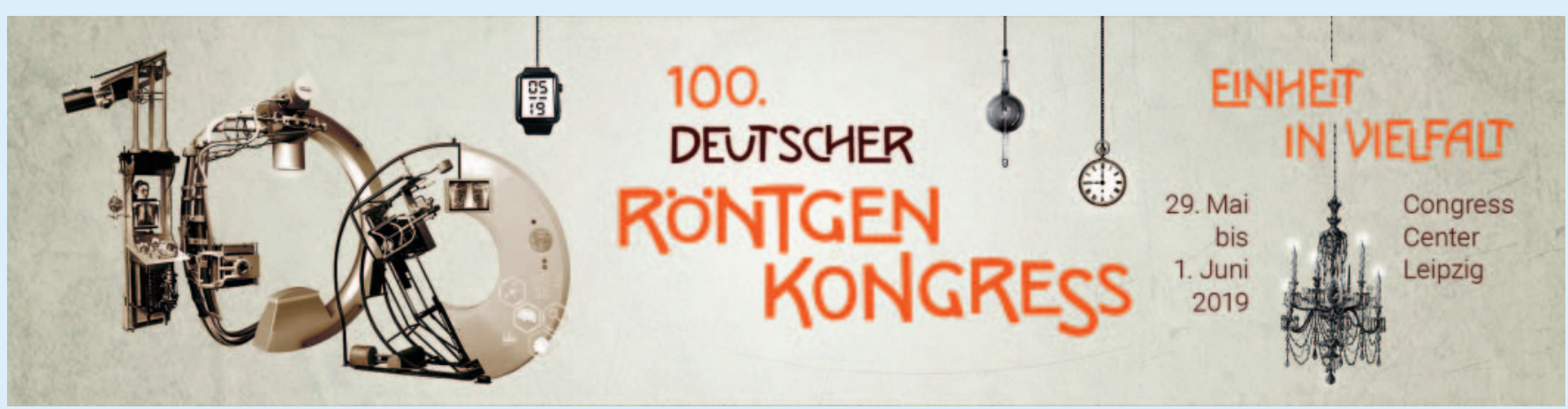

“RöKo International”, the English program at the German Radiology Congress, offers a broad spectrum of topics with speakers from all over Europe, from Asia and the USA. This year's topics are Oncologic Imaging, Interventional Imaging, Musculoskeletal Imaging, Cardiovascular Imaging, Chest imaging, Paediatric radiology, Abdominal Imaging and Breast Imaging.

\section{International Interpretation Quiz}

An undisputed highlight will be the International Intepretation Quiz on Wednesday. The quiz will feature five young and experienced international radiologists in their areas of expertise using two interesting clinical cases to be solved by each of them. Moreover, the image interpretation session will be interactive with the audience. The participants of the session which will be able to answer questions for each case ensuring that the presentations are lively and entertaining for the audience. Participants interested in the session are advised to please show up on time.

\section{KEY FACTS}

Wednesday, May 29,

12:30 pm to $1: 30 \mathrm{pm}$

Room Röntgen

Moderation: Prof. Dr. Marc Dewey, Berlin

\section{Guest of Honor from}

\section{overseas}

Another highlight: RNSA President Valerie P. Jackson, MD will honor the 100th German Radiology Congress with her pres- ence. As part of the session "Self-Management for young radiologists", she will be reporting about "The Value of the Right Side of the Brain in Leadership".

“SELF-MANAGEMENT FOR YOUNG RADIOLOGISTS"

Friday, 31th May 2019,

3:45 pm to 5:15 pm

Room Levy-Dorn

Moderation: Prof. Dr. Michael Forsting, Essen/Dr. Stefan Lohwasser, Berlin/ PD Dr. Peter Bannas, Hamburg

\section{3:45 pm - 4:10 pm}

The Value of the Right Side of the Brain in Leadership

Prof. Dr. Valerie Jackson 